JAZYKOVEDNÝ ČASOPIS, 2016, roč. 67, č. 1

\title{
МЕТОНИМИЯ И МЕТАФОРА КАК КОРРЕЛЯТЫ ДВУХ ЭТАПОВ ВЫНУЖДЕННО ПОВЕРХНОСТНОГО ВОСПРИЯТИЯ ВОЗМОЖНОСТИ СОЗДАТЬ НОВОЕ ЛЕКСИЧЕСКОЕ ЗНАЧЕНИЕ
}

\author{
СЕРГЕЙ ПОПОВ \\ Харьковский национальный университет имени В. Н. Каразина (Украина)
}

POPOV, Sergej: Metonymy and Metaphor as Correlates of Two Stages in Forcedly Superficial Perception of the Possibility to Create a New Lexical Meaning. Journal of Linguistics, 2016, Vol. 67, No 1, pp. $31-44$.

\begin{abstract}
For decades now, we are talking about that in science in general, and in linguistics in particular a structuralist paradigm is naturally complemented with an anthropocentric paradigm - with its inherent attention to human cognitive structures. Following the question "how?" we more and more often ask the question "why?". This is a logical way of development of human thought in the process of cognition of reality: first, based on the differential and integral signs, organize, and then wonder why the system looks exactly the way it looks, with its tendentiousness and illogicalities. The aim of the article is to study the correlation between lexical phenomena of metonymy and metaphor and cognitive structure of perception. This study is in line with a new scientific approach proposed by evolutionary epistemology: cognitive and evolutionary. This approach implies increased attention to human perception and logic in their evolution. Based on the information of anthroponimic sciences related to linguistics about degrees of perception and logics quality, this approach allows to see the deep reasons of phenomena being studied.
\end{abstract}

Key words: metonymy, metaphor, perception, logics, evolution

В последние годы языковеды часто говорят о том, что в современной лингвистике на смену лингвоструктурализму стремительно идет или уже фактически пришел антропоцентризм, настаивающий на выявлении связи языковых явлений с когнитивными структурами носителей языков. Если оценить это явление объективнее, а следовательно корректнее, то, видимо, следует говорить о том, что антропоцентризм вообще и когнитивная лингвистика в частности не сменяют, а дополняют заслуживающие уважения достижения лингвоструктурализма. И такое дополнение, вне всяких сомнений, научно неизбежно.

Одним из главных требований когнитивной науки вообще и когнитивной лингвистики в частности является объяснение (в дополнение к закономерно применявшемуся при структурализме описанию) явлений действительности вообще и языковых явлений в частности: наряду с вопросами «как?» должны ставиться вопросы «почему?» (Кибрик, 1992, с. 17). Если выйти за пределы лингвистики и обратить взор на другие науки, станет понятно, что все более свойственное современной лингвистике дополнение описательности объясни- 
тельностью является фрагментом общей научной картины: когда нечто научно воспринятое научно описано (систематизировано), неизбежно возникает когнитивная по своей сути потребность научно объяснить, почему описанное имеет именно такую форму и именно такое содержание.

Лексические явления метафоры и метонимии (в начале статьи представляем их в традиционном порядке) в различных их аспектах можно признать описанными вполне основательно (обзор таких исследований - см., например, в Арутюнова, 1990а; Арутюнова, 1990б). Ученые обращали внимание и на связь этих явлений с мышлением, демонстрируя тем самым когнитивный подход к языковым структурам в то время, когда о когнитивистике еще не говорили. Еще И. М. Сеченов обратил внимание на то, что в осмысливаемой человеком действительности существует три категории отношений: непосредственно соотносимое с метафорой «сходство», соотносимое с метонимией по признаку пространственной смежности «сосуществование» и соотносимое с метонимией по признаку временной смежности «последование» (Сеченов, 1952, с. 278). Понятийно важные для метафоры отношения сходства, а для метонимии отношения смежности в тех или иных терминах отмечались И. А. Бодуэном де Куртенэ, Н. В. Крушевским и Ф. де Соссюром. Не вызывает сомнений корреляция метафоры с понятиями парадигматики, языка и - в философском плане - с понятиями абстрактности и теории, а метонимии - с понятиями синтагматики, речи и - в философском плане - с понятиями конкретности и практики (см. об этом Кубрякова, 1990а; Кубрякова,1990б). Когнитивная значимость дихотомии метафоры и метонимии подчеркивается исследованиями афазии: все отмеченные нейропсихологами виды афазии (см., например, Лурия, 1947, с. 67 - 273; Лурия, 1962, с. 70 - 253), как убедительно доказано Р. О. Якобсоном, четко делятся на две группы: соотносимые с метафорой и соотносимые с метонимией (Якобсон, 1985; Якобсон, 1990).

Общепризнанным когнитивным прорывом в деле изучения метафоры (и в определенной мере - метонимии) явилась когнитивная (концептуальная) теория метафоры Дж. Лакоффа и М. Джонсона, основы которой представлены в монографии 1980 года (Лакофф, Джонсон, 2004). Основной тезис этой теории сводится к идее о том, что суть процесса метафоризации состоит в обработке фрагментарных структур (фреймов и сценариев) знаний как опыта взаимодействия человека с окружающим - объектным и социальным - миром. Согласно этой теории метафоризация представляет собой повторение в структуре знания «цель» некоторых областей структуры знания «источник». Для когнитивистов Дж. Лакоффа и М. Джонсона совершенно очевидно, что естественный язык метафоричен потому, что метафорично человеческое мышление: «Итак, самое важное утверждение, которое мы сделали, - это то, что метафора принадлежит не только языку, т. е. не только словам. Мы утверждаем, что проиеессы человеческого мышления во многом метафоричны. Это то, что имеется 
в виду, когда мы говорим, что концептуальная система человека структурирована и определена с помощью метафоры. Метафоры как выражения естественного языка возможны именно потому, что они являются метафорами концептуальной системы человека» (Лакофф, Джонсон, 2004, с. 27). Однако данная теория не дает ответов на интересующие нас вопросы: «Почему человеческое мышление метафорично?», «Почему метафорическая проекция представляет собой перенос в структуру знаний «цель» лишь некоторых, причем, возможно, весьма определенных, областей структуры знаний «источник»?» (ср. констатацию, но не объяснение создателями этой теории того, что «метафорическое структурирование понятийных областей оказывается частичным, а не глобальным. Если бы оно было глобальным, то один концепт абсолютно совпадал бы с другим, а не просто понимался в его терминах. Например, реально время это не деньги» (Лакофф, Джонсон, 2004, с. 33 - 34), «Почему метафорическая проекция имеет именно такой вид?». Аналогичные вопросы уместны и в отношении когнитивных корреляций метонимии. И важно признать, что постановка таких вопросов полностью соответствует упомянутому выше когнитивному принципу объяснительности.

Одним из принципов когнитивной лингвистики является междисциплинарность. Как верно заметил А. Е. Кибрик, «все, что имеет отношение к существованию и функционированию языка, входит в компетенцию лингвистики» (Кибрик, 1992, с. 20). Именно такой, междисциплинарный, подход к изучению метафоры можно видеть в известной монографии В. Крупы, в которой автор, справедливо обращая внимание на антропоцентрически познавательную и, следовательно, инновационную ценность метафоры, рассматривает соотношение понятия метафоры с теорией лингвистической относительности, изучает метафору как творчество, одновременно отрицающее и созидающее языковую конвенциональность в «критических ситуациях» потребности в новом значении и потенциального непонимания новой метафоры реципиентом (этнические различия, пиджинизация), исследует корреляции метафор с весьма досконально им изученными мифами разных народов, анализирует метафоры поэтические, в том числе народно-поэтические с присущими им стереотипами, метафоры шизофренические и детские, дифференцирует метафоры научные и лексические, представляет метафорические модели образности в поэзии и метафоричность в грамматике, показывает корреляции метафоры с тропами, комментирует понимание Р. О. Якобсоном понятий метафоры и метонимии (Krupa, 1990). В соответствии с данной междисциплинарной традицией считаем возможным и необходимым при изучении когнитивных корреляций переносных - не только метафорических, но и метонимических - значений обращаться к результатам, полученным в смежных с лингвистикой антропонауках (науках о человеке), прежде всего в психологии, нейрофизиологии и логике. 
В данной монографии и в более поздних статьях В. Крупа периодически касается вопросов восприятия метафор. Так, в статье 1997 года автор приходит к выводу, что метафоры, демонстрирующие сходство в целом очень разных по набору семантических признаков лексем, могут быть разделены на метафоры, основанные на сходстве, очевидном для подавляющего большинства носителей языка, и метафоры, основанные на сходстве, очевидном далеко не для всех таких носителей, и именно последнее, редкое сходство представляется «оригинальным», удивительным» и «впечатляющим» (Krupa, 1997, s. 87). В статье 2010 года В. Крупа рассматривает метафоры в «критических коммуникативных ситуациях», под которыми понимает такое положение дел, когда для некоторых людей вполне известные (не авторские) метафоры не могут адекватно выразить намерения говорящего (Krupa, 2010). Из этого следует, что разные носители языка одни и те же потенциально метафорообразующие явления воспринимают не всегда одинаково.

Для нас же это означает, что когнитивисты - исследователи не только метафоры, но и метонимии имеют все основания обратить внимание на корреляции метафоры и метонимии с такой эпистемологически важной когнитивной структурой, как восприятие (перцепция). Для нас очевидно, что не случайно сегодня уже хрестоматийный когнитивный труд Дж. Лакоффа и М. Джонсона, о котором мы говорили двумя абзацами выше, заканчивается словами: «Способность понимать опыт с помощью метафоры - это как одно из чувств, как видение, осязание или слух; обращение к метафорам остается единственным способом восприятия и осознания в опыте большей части действительности. Метафора - такая же важная и ценная часть нашей жизни, как, например, осязание» (Лакофф, Джонсон, 2004, с. 253). Столь прямое соотнесение метафоры с когнитивной структурой восприятия является еще одним свидетельством необходимости сконцентрировать внимание на корреляциях восприятия как с метафорой, так и с метонимией.

Изучение таких корреляций и является целью настоящей статьи, специализирующейся на выяснении перцептивных причин возникновения, существования и алгоритмического устройства метонимии и метафоры. Данное исследование находится в русле когнитивно-эволюционного подхода, предложенного современной эпистемологией (Меркулов, 2003; Меркулов, 2006) и примененного при изучении регулярной грамматической вариантности в русском языке (Попов, 2015).

Долгое время восприятие считалось самодостаточным средним звеном между ощущением и представлением, рассматривалось как чувственный образ, который формируется на основе ощущений и является основой представления (Кондаков, 1975, с. 92 - 93, 429, 475). Современное видение соотношения ощущения, восприятия и представления отличается от указанного традиционного и состоит в том, что соотношение ощущения и восприятия выглядит 
пространственным, расположенным по вертикали: восприятие находится выше ощущения, - в то время как отличие восприятия от представления не является пространственным и, следовательно, расположенным по вертикали - это отличие временное: представление наблюдается позже восприятия, поскольку, «воспроизводя в нашей памяти прежние восприятия, мы имеем представление о предметах» (Войшвилло, 1994, с. 7). «Восприятие - это «форпост» жизненного, познающего опыта человека, хранимого в памяти», - заметил в свое время один из пионеров психолингвистики Н. И. Жинкин (Жинкин, 1982, с. 52). Следовательно, представление есть «восприятие по памяти», то есть иметь представление - это помнить то, что было воспринято, и потому всегда мысленно это воспринимать. Из этого следует, что, имея такое тесно связанное с мышлением понятие восприятия, можно обойтись без понятия представления, поскольку оно толкуется через понятия восприятия и памяти, и выделять два вида восприятия: непосредственное или с участием памяти.

В когнитивной психологии, то есть относительно современном направлении психологической науки, утвердилось качественно обоснованное убеждение, что восприятие выполняет когнитивную функцию категоризации фиксируемых «правым мозгом» чувственных данных, осуществляемую (по умолчанию - у правшей) левым мозговым полушарием, то есть является важнейшей частью мышления: базой, на которую мышление опирается (Брунер, 1977, с. 23 - 26; Гибсон, 1988, с. 366; Найссер, 1981, с. 23, 30; Солсо, 2011, с. 95; Андерсон, 2002, с. 44; Величковский, 2006, с. 208). Будучи базовой частью мыслительного процесса, восприятие обеспечивает категоризированными данными строй мышления - логику. Из этого следует, что качество логики - логичность - прямо зависит от качества восприятия, которое поставляет мышлению данные, закладываемые в основания стихийно формируемых силлогизмов: если поставленные восприятием сведения оказались ошибочными, ошибочным будет и вывод - при полной безупречности силлогистического механизма, например Все мужчины любят мандарины (ложное основание, ведь на самом деле далеко не все мужчины любят мандарины) - Сократ мужчина (вторая, верная, посылка), - Следовательно, Сократ любит мандарины (ложный - из-за ложности основания - вывод, венчающий формально безупречный силлогизм). В свою очередь понятие качества восприятия позволяет говорить о его градации, о разных его степенях.

На основании сведений о развитии логических способностей у ребенка, первобытного человека и современного цивилизованного взрослого психологи выделяют три степени восприятия: 1) синкретичное восприятие, то есть восприятие явления в целом виде, не дифференцированное по признакам, не позволяющее осуществить категоризацию; 2) поверхностное восприятие, то есть восприятие лишь одного, как правило ближайшего, из признаков явления, находящихся в эмпирически достоверной зоне, часто приводящее к неверной ка- 
тегоризации явления; 3) альтернативное восприятие, то есть восприятие всех признаков явления, находящихся в эмпирически достоверной зоне, позволяющее осуществить объективную категоризацию альтернативно-императивно, обоснованно отвергая один признак и предпочитая вместо него другой, и альтернативно-диспозитивно, принимая признаки как обоснованно сосуществующие (см. об этом Попов, 2013, 5 - 105).

В соответствии с когнитивным принципом объяснительности, упомянутым в начале статьи, при изучении каких-либо когнитивно-эволюционных корреляций лексических явлений метафоры и метонимии прежде всего необходимо объяснить причину переносов лексических значений. Еще И. М. Сеченов заметил, что обобщенность словарных значений является следствием ограниченности объема человеческой памяти: «Если бы человек запоминал каждое из впечатлений в отдельности, то от предметов наиболее обыденных, каковы, например, человеческие лица, стулья, деревья, дома и пр., составляющих повседневную обстановку нашей жизни, в голове его оставалось бы такое громадное количество следов, что мышление ими, по крайней мере в словесной форме, стало бы невозможным, потому что где же найти десятки или сотни тысяч разных имен для суммы всех виденных берез, человеческих лиц, стульев и как совладать мысли с таким громадным материалом?» (Сеченов, 1952, с. 317). Логично предположить, что ограниченностью объема памяти объясняется и неизбежность переносов лексических значений слов (о метафоре как о среднем, компромиссном звене между крайностями каузирующего переполнение человеческой памяти «открытого языка» и «антиязыковостью» «закрытого языка» пишет В. Крупа - Krupa, 1990, с. 12 - 13). Очевидно, стихийное присвоение одним и тем же, то есть не требующим специального запоминания, формам других, коммуникативно востребованных значений - мера вынужденная: обусловленная небезразмерностью человеческой памяти.

Повсеместно наблюдаемое в ходе познания формальное сходство «нового» с «известным» описано - но не объяснено, в том числе каузацией мнемоническим недостатком, - психологами и биологами при освещении процесса познания и лингвистами при освещении грамматических явлений в целом и грамматических вариантов в частности (см. об этом Попов, 2014, с. 104 - 106).

Так, в свое время знаменитый детский психолог Ж. Пиаже пришел к выводу, что при восприятии и усвоении ребенком новых явлений «новый факт должен быть достаточно сходным с ранее известным, чтобы пробудить интерес, и вместе с тем достаточно отличным от него, чтобы не вызвать пресыщения» (Пиаже, 1969, с. 160). По мнению Л. С. Выготского, «всякое создание воображения всегда строится из элементов, взятых из действительности и содержащихся в прежнем опыте человека» (Выготский, 1991, с. 3 - 9). О восприятии чего-либо с опорой на известные сущности свидетельствуют многочисленные факты детского и первобытного восприятия (Попов, 2013, с. 18 - 78). Во всех 
детских и взрослых попытках категоризации очевидно «стремление объяснить новое через уже известное (или предполагаемое таковым)...» (Фрумкина, Михеев, Мостовая, Рюмина, 1991, с. 46). Известные биологи У. Матурана и Ф. Варела свидетельствуют, что «каждое новое единство неизменно начинает свою индивидуальную историю, обладая и структурным сходством со своими предками, и отличиями от них» (Матурана, Варела, 2001, с. 61).

В лингвистике принцип «Новое создается на базе известного» тоже хорошо известен. Согласно утвердившимся представлениям, новые значения крайне редко требуют к себе настолько повышенного внимания, чтобы для них создавались новые материальные оболочки. Б. А. Серебренников, выдвигая гипотезу о существовании особого типа мышления - «лингвокреативного» (Серебренников, 1983, с. 76 - 111), акцентирует внимание на том, что оно отражает окружающую человека действительность, опираясь на имеющиеся ресурсы языка: «Было бы неправильно предполагать, что для обозначения новых понятий или каких-либо отношений между понятиями язык прибегает к каким-то новым композициям фонем, к поискам еще не использованных сочетаний. Обычно для этих целей используют уже существующие знаки, подвергающиеся при этом различного рода преобразованиям и переосмыслениям...» (Серебренников, 1983, с. 106 - 109). В литературе, посвященной проблемам звукового восприятия речи, говорится о сегментном характере данного восприятия и о необходимости различать два вида такой сегментации: аналитическую сегментацию и перцептивную сегментацию. Аналитическая сегментация представляет собой научную процедуру разложения воспринимаемого текста на языковые единицы разного уровня. При перцептивной сегментации, которая и имеет место в повседневной коммуникации, «носитель языка, владеющий, естественно, языковой системой, должен в процессе восприятия речи представить спектрально-временной континуум акустического речевого сигнала в терминах уже известных ему дискретных языковых единиц», должен выяснить, «под какую из разрешенных в языке фонемных последовательностей можно подвести воспринимаемый отрезок звучащего текста», поскольку перцептивная сегментация «необходима лишь постольку, поскольку ее результаты влияют на идентификацию языковых единиц» (Венцов, Касевич, 2003, с. 65 - 66). Э. КарстейрсМаккарти приходит к выводу, что происхождение морфологии связано с появлением возможности восприятия незначительных изменений знаков при их сочетании, которые стали осознаваться как «те же, но другие». В результате такого осознания носители знаковой системы начинают обращать внимание на различия между вариантами знаков, после чего эти различия закрепляются (Carstairs-McCarthy, 2005). По мнению С. А. Бурлак, «накопление знаков с какого-то момента начинает давать возможность создавать новые знаки не на базе реальных ситуаций, а на базе уже известных знаков, несколько модифицируя их» (Бурлак, 2011, с. 372). Исследования последних десятилетий показыва- 
ют, что в течение XX века в русской грамматике «резкого обновления в составе варьирующихся форм не происходило. Не ломка, а перестройка в соотношении одних и тех же единиц - так можно характеризовать процесс обновления грамматической нормы» (Граудина, 1980, с. 17).

Несложно убедиться в том, что приведенные аргументы применимы и к обоснованию формального сходства прямых и переносных лексических значений: гораздо легче запомнить новое - коммуникативно востребованное - значение, если оно закреплено не за вновь (с нуля) созданной или недавно заимствованной формой, а за формой хорошо известной. Но, в отличие от формального сходства в грамматике, всегда предполагающего небольшие формальные различия, формальное сходство переносных лексических значений является абсолютным (как известно, семантические различия между прямыми и переносными лексическими значениями проявляются в синтагматике форм-носителей).

Соотнеся приведенные сведения со степенями восприятия, можно прийти к выводу, что принцип «Новое создается на базе известного», являющийся слабым объяснением сходства грамматических вариантов как не объясняющий причину данной принципиальности, представляет собой констатацию результата действия такого когнитивного механизма, как вынужденно поверхностное восприятие возможности создания новой грамматической единицы с новой семантической или стилистической характеристикой: при создании такой единицы воспринимается только одна, наиболее простая и заметная в первую очередь возможность, а именно создание такой единицы на базе уже имеющейся за счет незначительного формального изменения последней. Например, формальное различие суффиксов в туристский и туристический позволяет различать эти прилагательные как выражающие отношение соответственно к туристу и туризму, а разные формы числа сказуемого в Несколько человек курит или Несколько человек курят позволяют дифференцировать цельность и партитивность восприятия субъектов действия.

Логично считать, что именно вынужденно поверхностное восприятие возможности присвоить новое лексическое значение является причиной абсолютного формального сходства прямых и переносных лексических значений, ведь для создания последних используются формы прямых значений. Здесь возможно убедительное доказательство от противного. У первобытных, как и у наиболее древних, народов нет обобщенных и переносных лексических значений и нет абстрактных существительных. Лексические значения конкретны, и запоминаются они потому, что их относительно немного вследствие относительного невысокого уровня познания действительности, обусловливающего относительно небольшое число коммуникативно востребованных номинаций. Показательный пример таких закономерностей дает Б. Л. Уорф, когда сравнивает метафоричность английского и аметафоричность изучаемого им индейского 
языка хопи (метафоры взяты автором в кавычки): «Я «схватываю» «нить» рассуждений моего собеседника, но если их «уровень» слишком «высок», мое внимание может «рассеяться» и «потерять связь» с их «течением», так что, когда он «подходит» к конечному «пункту», мы расходимся уже «широко» и наши «взгляды» так «отстоят» друг от друга, что «вещи», о которых он говорит, «представляются» очень условными или даже «нагромождением» чепухи. Поражает полное отсутствие такого рода метафор в хопи» (Уорф, 1960, с. 151). То, что поражает Б. Л. Уорфа, вполне объяснимо: индейцы хопи, демонстрируя скромные результаты познания действительности, еще не пришли к стихийной метафоризации своей лексики, поскольку еще не ощутили такой коммуникативной потребности: по крайней мере, век назад количество имеющихся в языке хопи коммуникативно востребованных номинаций их память вмещала вполне беспроблемно.

Поскольку речь идет о двух разновидностях переноса лексических значений - метафоре и метонимии, важно рассмотреть механизмы вынужденно поверхностного восприятия возможности таких переносов в сравнении. Такое рассмотрение позволит обнаружить градационные нюансы такого восприятия указанной возможности.

Очевидно, что метонимия со свойственным ей переносом по смежности представляет собой наиболее простой случай вынужденно поверхностного восприятия. Это восприятие возможности присвоить той же форме значение того, что находится совсем рядом, граничит с названным той же формой в одном семантическом поле пространства (например, 'действие - место действия': сделать остановку - подъехать к остановке; 'вместилище - его содержимое': вода в чайнике - вскипятить чайник) или времени (например, 'действие - результат действия': сочинение рассказа - икольное сочинение; 'материал изделие из материала': добывать серебро - столовое серебро). Указанная пространственная или временная близость прямого и метонимического значений, то есть не очень контрастное их противопоставление, делает отличие метонимического значения от прямого значения не очень заметным: нефилологи такую переносность обычно не замечают. Этот случай можно рассматривать как первый (начальный) этап вынужденно поверхностного восприятия возможности создать новое лексическое значение.

В отличие от метонимии, метафора со свойственным ей переносом по сходству представляет собой принципиально иной случай вынужденно поверхностного восприятия. Это восприятие возможности присвоить той же форме значение не того, что находится совсем рядом в пространстве или времени, как в случае с метонимией, а того, что противопоставлено прямому значению гораздо более заметно, чем при метонимии. Основанием для переноса является, как правило, лишь одна - удачно оказавшаяся «на поверхности» воспринимаемого - сравнительная по своей функции сема, общая для двух сущностей, на- 
пример ‘упрямство’ и/или 'глупость': Осел не хотел тащцить повозку - Какой же ты, Иван, осел; 'перемещение вверх, то есть на более заметное и подобающее место': поднять упавшую на пол газету - поднять вопрос о членстве в $E C$; 'воздействие на организм и психику человека': горячий, теплый или холодный чай-горячий, теплый или холодный прием. Следовательно, об общем семантическом пространстве, в котором несложно найти смежное явление, как это наблюдается при метонимии, в случаях с метафорой говорить не приходится. Сущность, получившая метафорическое значение, всегда имеет прямое значение, которое с производным от него метафорическим значением в одном семантическом пространстве не пребывает. Так, названный ослом Иван - 'человек мужского пола', у применяемого в значении 'актуализировать' глагола поднять - прямое значение 'взять, подобрать что-либо лежащее (на полу, земле и т. п.)', у применяемых в значении 'оценочно-эмоциональное воздействие на психику’ прилагательных горячий, тепльй, холодныц - прямые значения «буквально» эмпиричны: соответственно 'имеющий высокую температуру', 'дающий тепло, являющийся источником тепла', 'имеющий низкую температуру’. Семантико-понятийная дистанция - между человеком и ослом, поднятием чего-либо с пола и актуализацией какого-либо вопроса, температурой чего-либо эмпирически достоверно физического и психической, нередко эмоциональной реакцией человека на какое-либо событие - в результате метафорического переноса оказывается достаточно ощутимой. Данная контрастность и делает метафорические переносы более заметными, чем переносы метонимические, и обеспечивает хорошо известную «живую образность» метафоры, которую способны замечать не только филологи. Заметность контраста прямого и метафорического значений приближает восприятие возможности создать метафору к альтернативному восприятию, однако формальная одинаковость прямого и метафорического значений все же не позволяет отказаться от объяснения этого факта перцептивной поверхностностью. Все это обусловливает достаточно четкое и в то же время компромиссное понимание того, что метафорические переносы представляют собой более сложный, близкий к альтернативности случай вынужденно поверхностного восприятия возможности создать новое лексическое значение, чем это наблюдается при метонимических переносах. Поскольку это более сложный в сравнении с метонимией случай поверхностного восприятия, его можно рассматривать как второй этап вынужденно поверхностного восприятия возможности присвоить новое лексическое значение, более близкий к степени альтернативного восприятия.

В заключение констатируем следующее:

Несомненно, присвоение каждому новому значению новой лексической формы было бы логически идеальным. Именно этот принцип лежит в основе хорошо известного требования немногозначности научных терминов. Наука 
как форма общественного сознания не может не стремиться к идеалу абсолютной непротиворечивости, иначе ей грозит утрата самоидентичности. Однако идеальная логичность такой коммуникативной системы, как язык, который, по свидетельству К. Ажежа, логики называют естественным «с двусмысленной смесью снисходительности и уважения» (Ажеж, 2003, с. 135), логичен весьма относительно - по разным, но неизменно антропоцентрическим причинам.

Появление и существование метонимии и метафоры, по-своему обогащающих язык и новыми лексическими значениями, и новой, нередко экспрессивноэмоциональной значимостью, объясняются биолого-когнитивным фактором недостаточности объема человеческой памяти. Взятые отдельно метонимический и метафорический переносы лексического значения коррелируют соответственно с двумя этапами вынужденно поверхностного восприятия: простым, начальным и более сложным, близким к альтернативному восприятию.

Научно перспективным представляется осуществление подробного исследования перцептивных корреляций метонимических и метафорических переносов лексических значений в разных языках.

\section{Литература}

АЖЕЖ, Клод: Человек говорящий: Вклад лингвистики в гуманитарные науки: Москва: Едиториал УРСС 2003. $304 \mathrm{cc}$.

АНДЕРСОН, Джон: Когнитивная психология. Санкт-Петербург: Питер 2002. 496 сс.

АРУТЮНОВА, Нина Д.: Метафора. В: Лингвистический энциклопедический словарь. Москва: Сов. Энциклопедия 1990а, сс. 296 - 297.

АРУТЮНОВА, Нина Д.: Метонимия. В: Лингвистический энциклопедический словарь. Москва: Сов. Энциклопедия 1990б, сс. 300 - 301.

БРУНЕР, Джером: Психология познания. За пределами непосредственной информации. Москва: Прогресс 1977. 413 сс.

БУРЛАК, Светлана: Происхождение языка: Факты, исследования, гипотезы. Москва: Астрель CORPUS 2011. 464 сс.

ВЕЛИЧКОВСКИЙ, Борис М.: Когнитивная наука: Основы психологии познания. В 2 т. Т. 1. Москва: Смысл: Издательский центр «Академия» 2006. 448 сс.

ВЕНЦОВ, Анатолий В. - КАСЕВИЧ, Вадим Б.: Проблемы восприятия речи. Москва: Едиториал УРСС 2003. 240 сс.

ГИБСОН, Джером: Экологический подход к зрительному восприятию. Москва: Прогресс 1988. $464 \mathrm{cc}$.

ГРАУДИНА, Людмила К.: Вопросы нормализации русского языка. Грамматика и варианты. Москва: Наука 1980. 288 сс.

ЖИНКИН, Николай И.: Речь как проводник информации. Москва: Наука 1982. 160 сс.

КИБРИК, Александр Е.: Очерки по общим и прикладным вопросам языкознания (универсальное, типовое и специфичное в языке). Москва: Издательство МГУ 1992.336 сс.

КОНДАКОВ, Николай И.: Логический словарь-справочник. Москва: Наука 1975. 720 сc.

КУБРЯКОВА, Елена С.: Парадигматика. В: Лингвистический энциклопедический словарь. Москва: Сов. Энциклопедия 1990а, сc. 366 - 367. 
КУБРЯКОВА, Елена С.: Синтагматика. В: Лингвистический энциклопедический словарь. Москва: Сов. Энциклопедия 1990б, сс. $447-448$.

ЛАКОФФ, Джордж - ДЖОНСОН, Марк: Метафоры, которыми мы живем. Москва.: Едиториал УРСС, 2004. $256 \mathrm{cc}$.

ЛУРИЯ, Александр Р.: Травматическая афазия: клиника, семиотика и восстановительная терапия. Москва: Издательство Академии медицинских наук СССР 1947. 367 сc.

ЛУРИЯ, Александр Р.: Высшие корковые функции человека и их нарушения при локальных поражениях мозга. Москва: Издательство Московского университета 1962. $432 \mathrm{cc}$.

МАТУРАНА, Умберто - ВАРЕЛА, Франциско: Древо познания: Биологические корни человеческого понимания. Москва: Прогресс-Традиция 2001. 224 сс.

МЕРКУЛОВ, Игорь П.: Эволюционная эпистемология: проблемы, перспективы. Т. 1. СанктПетербург: Издательство РХГИ 2003. 471 сс.

МЕРКУЛОВ, Игорь П.: Эпистемология (когнитивно-эволюционный подход). Т. 2. - СанктПетербург: Издательство РХГА 2006. 416 сc.

НАЙССЕР, УЛрик: Познание и реальность: Смысл и принципы когнитивной психологии. Москва: Прогресс 1981. 232 сс.

ПИАЖЕ, Жан: Психология интеллекта. В: Пиаже Ж. Избранные психологические труды. Психология интеллекта. Генезис числа у ребенка. Логика и психология. Москва: Просвещение 1969 , cc. $55-231$.

ПОПОВ, Сергей Л.: Когнитивные основания эволюции форм русского синтаксического согласования: Монография. Харьков: НТМТ 2013. $150 \mathrm{cc.}$

ПОПОВ, Сергей Л.: Русская грамматическая вариантность в когнитивно-эволюционном освещении: Монография. Харьков: Міськдрук 2014. 304 сc.

ПОПОВ, Сергей Л.: Грамматические варианты в русском языке: когнитивно-эволюционный аспект: Дис. ... докт. филол. наук. Харьков, 2015. 453 сс.

СЕРЕБРЕННИКОВ, Борис А.: О материалистическом подходе к явлениям языка. Москва: Наука $1983.319 \mathrm{cc}$.

СЕЧЕНОВ, Иван М.: Элементы мысли. В: Сеченов И. М. Избранные произведения. Т. 1. Физиология и психология. Москва: Издательство АН СССР 1952, сc. 272 - 426.

СОЛСО, Роберт: Когнитивная психология. Санкт-Петербург: Питер 2011. 589 сc.

УОРФ, Бенджамин Л.: Отношение норм поведения и мышления к языку. В: Новое в лингвистике. Вып. 1. Москва: Издательство иностранной литературы, 1960, сс. 135 - 168.

ФРУМКИНА, Ревекка М. - МИХЕЕВ, Алексей В. - МОСТОВАЯ, Анна Д. - РЮМИНА, Наталья А.: Семантика и категоризация. Москва: Наука 1991. 168 сc.

ЯКОБСОН, Роман: Два аспекта языка и два типа афатических нарушений. В: Теория метафоры: Сборник. Москва: Прогресс 1990, сс. 110 - 132.

ЯКОБСОН, Роман: Лингвистические типы афазии. В: Р. Якобсон. Избранные работы: Сборник. Москва: Прогресс 1985, сс. $287-300$.

CARSTAIRS-MCCARTHY, Andrew: The evolutionary origin of morphology. In: Language origins: Perspectives on evolution. Oxford: Oxford Univ. Press 2005, pp. 166 - 184.

KRUPA, Viktor: Metafor in critical communicative situations. In: Asian and African studies, 19, 2010, 2, s. $344-350$.

KRUPA, Viktor: Metafora na rozhraní vedeckých disciplín. Bratislava: Tatran, 1990. $184 \mathrm{~s}$.

KRUPA, Viktor: Podobnost' ako základ metafory? In: Jazykovedný časopis, 48, 1997, č. 2, s. 81 -88 . 


\section{Resumé}

\section{METONYMIA A METAFORA AKO KORELÁTY DVOCH ETÁP PODMIENENEJ POVRCHNEJ PERCEPCIE MOŽNOSTI VYTVORIŤ NOVÝ LEXIKÁLNY VÝZNAM}

Ciel’om štúdie je preskúmat' vzájomný vzt’ah lexikálnych fenoménov metafory a metonymie s takou dôležitou kognitívnou štruktúrou, ako je percepcia. V štúdii sa aplikuje nový, v súčasnej epistemológii uplatňovaný kognitívno-evolučný vedecký prístup. Takýto prístup predpokladá zvýšenú pozornost' voči l'udskému vnímaniu a logike, ktoré skúma v ich evolúcii. Využíva poznatky o stupňoch percepcie a kvalite logiky antropocentrických vied súvisiacich s jazykovedou, pričom odhal'uje híbkové príčiny skúmaných javov.

Súčasný stav vývinu psychologickej vedy dovol’uje konštatovat', že človek má tri stupne percepcie, ktorej základnou funkciou je kategorizácia: 1. synkretická percepcia, t. j. vnímanie javu ako celku, nediferencované z hladiska príznakov, neumožňujúce kategorizáciu; 2. povrchná percepcia, t. j. vnímanie len jedného (obyčajne najbližšieho) z príznakov javu nachádzajúcich sa $\mathrm{v}$ empiricky hodnovernej zóne; takéto vnímanie často vedie $\mathrm{k}$ nesprávnej kategorizácii javu; 3. alternatívna percepcia, t. j. vnímanie všetkých príznakov javu nachádzajúcich sa v empiricky hodnovernej zóne, čo dovol'uje vykonat' objektívnu kategorizáciu.

Formálnu podobnost' „nového“ so „známym“, nevyhnutnú v procese poznania, opísali psychológovia a biológovia pri objasňovaní kognitívnych procesov a lingvisti pri výklade gramatických javov. Vysvetl'uje sa to povrchnou percepciou možnosti kategorizovat' „nové“: to, čo sa podobá na niečo známe, si možno l’ahšie zapamätat'. Princíp „nové sa vytvára na základe starého“ však možno aplikovat’ aj na objasnenie súvzt’ažnosti priamych a prenesených lexikálnych významov: nový význam si možno zapamätat' ovel'a l'ahšie, ak nie je fixovaný na novovytvorenú alebo nedávno prevzatú formu, ale na formu, ktorá je dobre známa. Príčinami formálnej podobnosti gramatických javov a prenesenosti formálne zhodných lexikálnych významov sú obmedzenost' objemu l’udskej pamäti (na čo upozorňoval už I. M. Sečenov) a povrchná percepcia možnosti vytvárat' nové lexikálne významy. Obidve tieto príčiny spoločne dovol'ujú hovorit' aj o podmienenom charaktere povrchnej percepcie takej možnosti.

Metonymia, ktorej východiskom je prenos na základe súvislosti, predstavuje najjednoduchší prípad podmienenej povrchnej percepcie. Toto vnímanie možnosti priradit’ tej istej forme význam toho, čo sa nachádza $\mathrm{v}$ bezprostrednom dosahu, hraničí $\mathrm{s}$ tým, čo tá istá forma pomenúva $\mathrm{v}$ jednom sémantickom poli priestoru (napr. ,dej - miesto deja': rus. sdelat' ostanovku, urobit' zastávku' - podjechat' k ostanovke ,podíst' vozidlom k zastávke') alebo času (napr. ,dej - výsledok deja': rus. sočinenije rasskaza,napísanie poviedky“ - školnnoje sočinenije, školská slohová práca'). Tento prípad možno hodnotit’ ako prvú (začiatočnú) etapu podmienenej povrchnej percepcie možnosti vytvorit’ nový lexikálny význam.

Na rozdiel od metonymie metafora, ktorej východiskom je prenos na základe podobnosti, predstavuje zásadne iný prípad podmienenej povrchnej percepcie. Ide tu o vnímanie možnosti priradit’ tej istej forme význam nie toho, čo sa nachádza v bezprostrednom dosahu v priestore alebo čase, ako je to v prípade metonymie, ale toho, čo je viditel'nejšie ako pri metonymii, čo je v protiklade k priamemu významu. Východiskom pre prenos je obyčajne jedna séma (ktorá sa zhodou priaznivých okolností ocitne „na povrchu“ vnímaného), funkčne porovnatel'ná a spoločná pre dve entity, napr. ,tvrdohlavost" a/alebo ,hlúpost': rus. Osiol ne chotel taščit' povozku, Somár nechcel tahat' voz" - Kakoj že ty, Ivan, osiol ,Aký si len, Ivan, somár‘. Spoločný sémantický priestor, v ktorom nie je tažké nájst’ blízky jav, ako to pozorujeme pri metonymii, v prípade metafory neplatí. Entita, ktorá nadobudla metaforický význam, má vždy priamy význam a ten sa nenachádza $\mathrm{v}$ jednom sémantickom priestore s metaforickým významom od neho odvodeným, napr. Ivan označený ako somár je ,človek mužského pohlavia‘. Viditel'nost' pojmovej dištancie medzi priamym a metaforickým významom, napr. medzi človekom a somárom, približuje vnímanie možnosti vytvorit’ metaforu $\mathrm{k}$ alternatívnej percepcii, avšak formálna zhoda priameho a metafo- 
rického významu predsa len nabáda $\mathrm{k}$ tomu, aby sme neodmietli vysvetlenie tohto faktu perceptívnou povrchnost'ou. Toto všetko podmieňuje dostatočne zretel’né, ale zároveň kompromisné chápanie toho, že metaforické prenosy sú zložitejším prípadom (blízkym k alternatívnosti) podmienenej povrchnej percepcie možnosti vytvorit’ nový lexikálny význam než prenosy metonymické. Ked’že ide o prípad povrchnej percepcie, ktorá je zložitejšia ako metonymická, možno ju považovat' za druhú etapu podmienenej povrchnej percepcie možnosti vytvorit’ nový lexikálny význam, ktorá je bližšia k stupňu alternatívnej percepcie. 